\title{
Alih Teknologi Perawatan Otomotif Untuk Meningkatkan Life Skill Mekanik Sepeda Motor Di Kampung Pulo Geulis, Kelurahan Babakan Pasar, Kecamatan Bogor Tengah, Kota Bogor
}

\author{
Hasvienda M Ridlwan ${ }^{1}$, Muslimin ${ }^{2}$, Asep $\mathbf{Y}^{\mathbf{3}}$ \\ 1,2,3 Jurusan Teknik Mesin, Politeknik Negeri Jakarta
}

\begin{abstract}
Abstrak
Pengabdian Kepada Masyarakat merupakan salah satu poin penting Tri Darma Perguruan Tinggi. Jurusan Teknik Mesin, Politeknik Negeri Jakarta, tahun 2019 ini mengadakan program Pengabdian Kepada Masyarakat dengan mengangkat tema "Alih Teknologi Perawatan Otomotif Untuk Meningkatkan Life Skill Mekanik Sepeda Motor di Kampung Pulo Geulis, Kelurahan Babakan Pasar, Kecamatan Bogor Tengah, Kota Bogor." Perawatan dasar sepeda motor memang dibutuhkan bagi setiap yang memilki kendaraan. Akan tetapi tidak semua yang memiliki kendaraan bermotor bisa memilki kemampuan memperbaiki sepeda motornya. Tujuan dari pengabdian masyarakat ini adalah untuk membekali para peserta agar memiliki keahlian dalam merawat sepeda motornya, khususnya untuk perawatan dasar. Selain itu, tujuannya agar para peserta memilki pekerjaan yang berkaitan dengan otomotif. Jurusan Teknik Mesin, Politeknik Negeri Jakarta memberikan pelatihan sekaligus menghibahkan seperangkat peralatan (toolbox) untuk perawatan sepeda motor dengan memanfaatkan alat dan bahan yang relatif mudah diperoleh. Pertimbangannya, jika para peserta tidak dibekali peralatan perawatan sepeda motor, para peserta akan kesulitan untuk terus menggali mengaplikasikan ilmu yang diperoleh selama pelaksanaan pembejkalan. Metode yang digunakan untuk mencapai tujuan adalah dengan cara: 1) pembekalan teori tentang perawatan dasar sepeda motor. 2) praktik perawatan dasar sepeda motor. 3) bantuan perangkat perawatan dasar sepeda motor. 4) pendampingan. Hasil kegiatan dapat disimpulkan yakni kemampuan peserta tentang perawatan dasar sepeda motor meningkat setelah mengikuti kegiatan pelatihan ini. Hal tersebut dikarenakan pelatih menggunakan metode teori-praktik, dan peserta dibekali peralatan dan bahan untuk mempraktikkan sendiri sepeda motornya. Sehingga antusiasme peserta untuk mempraktikkan ilmu perawatan dasar sepeda motor juga meningkat.
\end{abstract}

Kata Kunci: sepeda motor, perawatan, dan pulo geulis 


\begin{abstract}
Community Service is one of the important points of Tri Darma Perguruan Tinggi. The Department of Mechanical Engineering, Jakarta State Polytechnic, held a Community Service Program in 2019 with the theme "Transfer of Automotive Maintenance Technology to Improve Motorcycle Mechanical Life Skills in Pulo Geulis, Babakan Pasar Village, Central Bogor District, Bogor City." motorbikes are indeed needed for every person who has a vehicle. But not all who have motorized vehicles can have the ability to repair their motorbikes. The aim of community service is to equip participants to have expertise in caring for their motorbikes, especially for basic maintenance. In addition, the aim is for participants to have work related to automotive. The Department of Mechanical Engineering, Jakarta State Polytechnic provides training as well as donating a set of equipment (toolboxes) for motorcycle maintenance by utilizing tools and materials that are relatively easy to obtain. The consideration, if the participants are not equipped with motorcycle maintenance equipment, the participants will find it difficult to continue to apply the knowledge gained during the training. The method used to achieve the objectives is by: 1) debriefing the basic maintenance of a motorcycle. 2) the practice of basic motorcycle maintenance. 3) motorcycle basic maintenance device assistance. 4) assistance. The results of the activity can be concluded that the ability of participants about basic maintenance of motorbikes increased after attending this training activity. That is because the trainer uses the theory-practice method, and the participants are equipped with equipment and materials to practice their own motorbikes. So that the enthusiasm of participants to practice basic maintenance of motorcycle science also increased.
\end{abstract}

Keywords: motorcycle, maintenance, and Pulo geulis 


\section{PENDAHULUAN}

Sabtu, 28 September 2019 telah dilaksanakan pengabdian masyarkat Jurusan Teknik Mesin, Politeknik Negeri Jakarta yang berlokasi di kampung Pulo Geulis yang berjarak \pm 45 kilo meter arah selatan Politeknik Negeri Jakarta. Secara geografis, Kampung Pulo Geulis merupakan salah satu destinasi wisata sejarah sekaligus religi di Kota Bogor. Lahan yang diapit aliran Sungai Ciliwung berlokasitepat di Kelurahan Babakan Pasar, Kecamatan Bogor Tengah, Kota Bogor. Tidak jauh dari land mark Kota Bogor, yaitu Tugu Kujang, dan Kebun Raya Bogor. Hanya 20 menit dari keluar tol Jagorawi, atau 40 menit dari Stasiun Bogor, dengan memutar Istana dan Kebun Raya terlebih dahulu.

Di pulau seluas 3.5 hektar ini, sangat padat penduduk dihuni oleh kurang lebih 2.500 jiwa; dengan kata lain kepadatannya sekitar 700 jiwa per hektare. Namun, padatnya penduduk dengan semakin beragam latar belakang sukudan agama tidak membuat kampung ini bermusuhan. Mereka sering mengadakan acara bersama, seperti bersih-bersih wihara, syukuran warga dan lainnya.

Jurusan Teknik Mesin Politeknik Negeri Jakarta melakukan salah satu kegiatan tri dharma perguruan tinggi yaitu Pengabdian Kepada Masyarakat di Kampung Pulo Geulis ini. Jurusan Teknik Mesin telah melakukan survei langsung dan berdiskusi dengan Ketua RW.04 Kampung Pulo Geulis terlihat mendapati suatu permasalahan yaitu tidak adanya tempat perawatan/ bengkel untuk sepeda motor di Kampung Pulo Geulis, Kelurahan Babakan Pasar, Kecamatan Bogor Tengah, Kota Bogor sedangkan populasi sepeda motor yang banyak, dengan tumbuhnya sekolah-sekolah dari SD, SMP, MA dan SMA/SMK maka tentunya merupakan sebuah peluang yang bagus untuk berwirausaha atau memiliki bengkel di daerah tersebut. Di samping itu juga masih banyak pemuda produktif di sana dalam status pengangguran yang memang tidak memiliki bekal keterampilan vokasi.

Untuk meningkatkan kualitas kecakapan hidup, kompetensi professional pada teknologi perawatan otomotif dan menumbuh kembangkan jiwa kewarausahaan, dipilih program Alih Teknologi Perawatan Otomotif Untuk Meningkatkan Life Skill Mekanik Sepeda Motor Di Kampung Pulo Geulis, Kelurahan Babakan Pasar, Kecamatan Bogor Tengah, Kota Bogor. Alih Teknologi yang akan dilakukan oleh Tim Jurusan Teknik Mesin dengan cara melakukan pendekatan proses pembelejaran dengan menjelaskan teori, demontrasi dan praktik langsung. Instruktur kegiatan berasal dari Dosen Jurusan Teknik Mesin Politeknik Negeri Jakarta. Materi alih teknologi meliputi berbagai macam kompetensi dasar tentang perawatan dan perbaikan sepeda. Materi kompetensi dasar bertujuan untuk membentuk skill para peserta agar mampu menangani kerusakan pada sepeda motor.

Pelatihan Alih Teknologi Perawatan Otomotif Untuk Meningkatkan Life Skill Mekanik Sepeda Motor Di
Kampung Pulo Geulis, Kelurahan Babakan Pasar, Kecamatan Bogor Tengah, Kota Bogor ini ke depannya para peserta diharapkan mengalami peningkatan pengetahuan dan skill agar setidaknya para peserta tidak mengandalkan bengkel untuk memperbaiki kendaraan yang telah rusak. Selain itu, para peserta diharapkan setelah memilki keahlian dalam melakukan perawatan dasar sepeda motor, maka para peserta juga membuka bengkel motor sendiri yang peralatannya sudah didapat dari hibah Jurusan Teknik Mesin Politeknik Negeri Jakarta.

Permasalahan yang dihadapi oleh para peserta adalah:

- Masih kurangnya pengetahuan warga Pulo Geulis tentang perawatan sepeda motor, terutama perawatan skala dasar.

- Rendahnya kemampuan warga tentang otomotif, terutama dalam melakukan perawatan dasar sepeda motor.

Kurangnya kesadaran warga tentang wirausaha sebagai upaya meningkatkan taraf ekonomi keluarga sebagai wujud usaha mengurangi tingkat pengangguran.

\section{METODE PELAKSANAAN}

\section{Kegiatan Pelatihan Alih Teknologi Perawatan Otomotif Untuk Meningkatkan Life Skill Mekanik Sepeda Motor dilaksanakan di Kampung Pulo Geulis, Kelurahan Babakan Pasar, Kecamatan Bogor Tengah, Kota Bogor. Metode yang dilaksanakan untuk mencapai} tujuan adalah :

1) Pelatihan atau pembekalan untuk meningkatkan pengetahuan tentang teknik perawatan sepeda motor level dasar dengan cara penyampaian materi langsung oleh instruktur yang terdiri atas beberapa dosen Teknik Mesin Politeknik Negeri Jakarta, yang dibantu oleh sejumlah mahasiswa Jurusan Teknik Mesin yang juga memilki kompetensi di bidang otomotif, khusunya mesin sepeda motor. Selain dibekali teori dasar, para peserta juga mendapatkan pendampingan secara intens dari instruktur dan asisten agar materi yang disampaikan benar- benar mampu diaplikasikan.

2) Setelah menjelaskan teori, para instruktur (dosen) dan asisten (mahasiswa) langsung mempraktikkan tata cara perawatan dasar sepeda motor, adapun media yang digunakan ialah motor miliki para peserta sendiri, baik motor sistem karburator maupun injeksi.

3) Hibah berupa bantuan paket toolbox untuk perawatan dasar sepeda motor, kemudian kompresor atau mesin pompa angin elektrik. 
Peralatan tangan (handtools) dan peralatan mesin (powertools.)

4) Konsultasi para peserta dengan instruktur seputar permasalahan pada sepeda motor.

1) Perawatan aki motor

2) Pengecekan pengisian baterai

3) Pengecekan ban

4) Pengecekan rantai

5) Pengecekan suspensi

6) Pengecekan level oli

7) Penggantian oli

8) Pengecekan busi

9) Membersihkan filter udara

10) Pengecekan karburator

11) Pengecekan rem

12) Penyetean lampu utama

13) Penyetelan lampu rem

5) Terakhir melakukan proses pendampingan selama proses pelatihan berlangsung dari awal hingga akhir. Hal tersebut dimaksudkan supaya para peserta benar-benar merasakan manfaat dari kegiatan pelatihan ini, dan dapat merasakan bahwa kegiatan pengabdian masyarakat ini tidak bersifat insidentil saja, artinya pasca pelaksanaan kegiatan pun akan dilakukan pendampingan hingga tiga tahun berikutnya.

\section{HASIL DAN PEMBAHASAN}

Kegiatan pengabdian kepada masyarakat dilaksanakan di halaman kantor Kelurahan Desa Babakan pasar. Sebelum acara dimulai, terlebih dahulu panitia mempersilakan para peserta untuk menyimak sambutan dan mengisi kuesioner pra pelaksanaan pelatihan dengan tema Alih Teknologi Perawatan Otomotif Untuk Meningkatkan Life Skill Mekanik Sepeda Motor. dilaksanakan di Kampung Pulo Geulis, Kelurahan Babakan Pasar, Kecamatan Bogor Tengah, Kota Bogor.

Kegiatan yang dilakukan oleh Jurusan Teknik Mesin Politeknik Negeri Jakarta ini dirasakan sangat bermanfaat oleh para peserta. Selain itu, antusiasme peserta selama mengikuti kegiatan ini, terlihat dari respon yang diberikan oleh peserta melalui banyaknya pertanyaan- pertanyaan yang diajukan oleh para peserta kepada instruktur.

Para peserta sangat tertarik melakukan praktik perbengkelan tersebut. Selain itu para peserta sangat senang dengan adanya pemberian paket toolbox yang diberikan oleh panitia pelatihan berupa satu paket peralatan kunci, kompresor, dan satu dus oli yang berisi 20 pcs.

\section{Pembahasan}

Dalam melaksanakan kegiatan pengabdian masyarakat tersebut, panitia membuat kuesioner sebagai alat ukur yang harus diisi sebelum dan sesudah acara dilaksanakan. Hasil pengukuran sebelum dan sesudah kegiatan ditampilkan pada Tabel berikut ini.

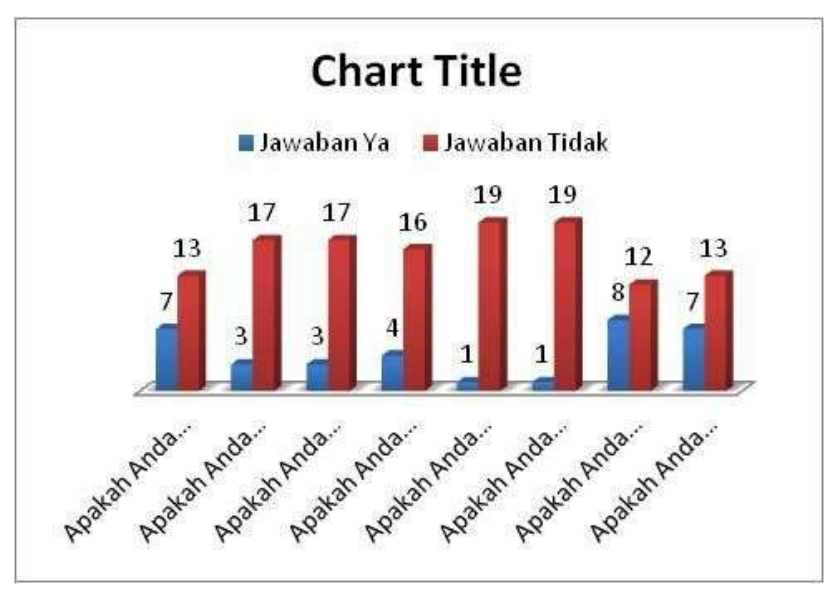

Grafik 1. Hasil pengukuran sebelum kegiata dilaksanakan

Berdasarkan hasil pengukuran di atas menggambarkan bahwa peserta pada umumnya tertarik untuk mengikuti Pelatihan Alih Teknologi Perawatan Otomotif Untuk Meningkatkan Life Skill Mekanik Sepeda Motor Di Kampung Pulo Geulis, Kelurahan Babakan Pasar, Kecamatan Bogor Tengah, Kota Bogor dengan antusias. Hal tersebut dikarenakan para peserta menganggap bahwa pelatihan tersebut merupakan suatu mengikuti kegiatan pelatihan serupa.

Berdasarkan hasil kuesnioner Sebelum pelaksanaan yang diisi oleh 20 peserta, diperoleh hasil bahwa $94 \%$ masih belum memahami cara perawatan dasar sepeda motor. Hasil selanjutnya tentang keterlibatan peserta dalam mengikuti pelatihan perawatan dasar sepda motor, hanya $6 \%$ yang pernah mengikuti pelatihan, dan $94 \%$ belum pernah mengikuti pelatihan sama sekali.

Berikutnya tentang pengalaman peserta mengenai pertanyaan tentang mengganti oli, filter udara, cek kampas rem hanya $5 \%$ yang pernah melakukan dan $95 \%$ belum. Begitupun dengan pemeriksaan rantai motor, $20 \%$ pernah melakukannya, dan 80 belum melakukan. 
Selanjutnya, partisipasi peserta dalam menilai instruktur baik dalam menjelasakan isi materi, maupun dalam membagi pengetahuan perawatan dasar sepeda motor, arahan, solusi pertanyaan, serta jawaban

95\% para peserta merasa puas. Selanjutnya untuk pertanyaan tentang peralatan bengkel yang disediakan, dan respon penyelenggaraan kegiatan ini, para peserta

$100 \%$ peserta merasa puas dan terbantu dengan adanya program pengabdian masyarakat ini.

Hal ini sudah dapat menjawab tujuan dari kegiatan ini adalah meningkatkan pengetahuan mitra dapat dicapai. Praktik yang ingin dicapai sebagai pola pikir baru unutk memiliki pembekalan life skill baru tentang teknik perawatan dasar sepeda motor agar terus ditingkatkan.

Grafik 2. Hasil pengukuran sesudah kegiatan

Setelah kegiatan dilaksanakan terjadi peningkatan terhadap pengetahuan teknik perawatan dasar sepeda motor meningkat drastis, dan seluruh item kuesioner sebagai alat ukur yang digunakan terjadi peningkatan yang sangat memuaskan.

Berdasarkan hasil kuesioner setelah pelaksanaan pelatihan yang diisi oleh 20 peserta, didapatkan hasil yang signifikan. Pertama penguasaan materi, $100 \%$ peserta telah memahami isi materi baik teori maupun praktik, diantaranya tentang ganti oli, cek rem, cek lampu, cek rantai, dan cek busi, dan cek karburator.

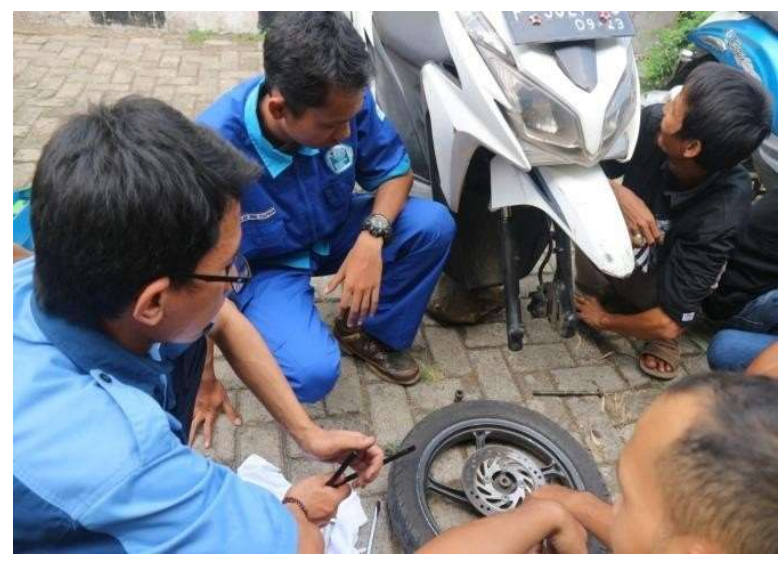

Gambar 1 Proses pembekalan materi dari instruktur pelatihan

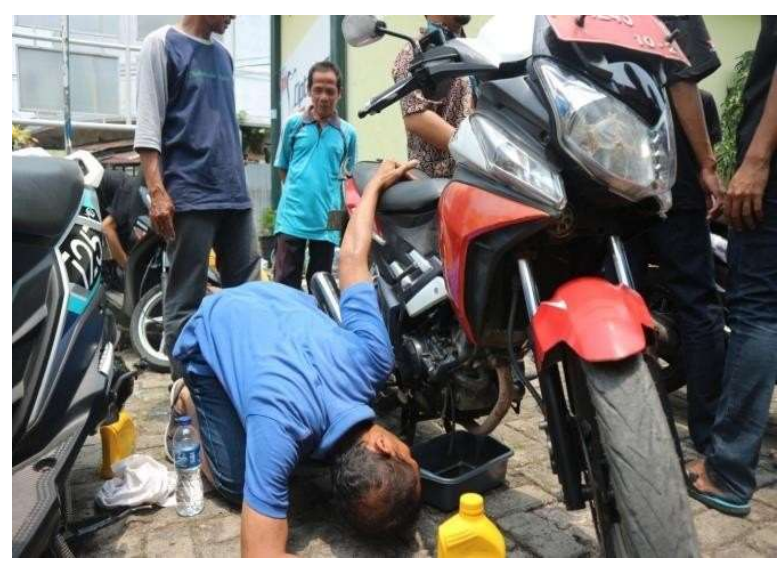

Gambar 2 Proses praktik perawatan dasar sepeda motor 


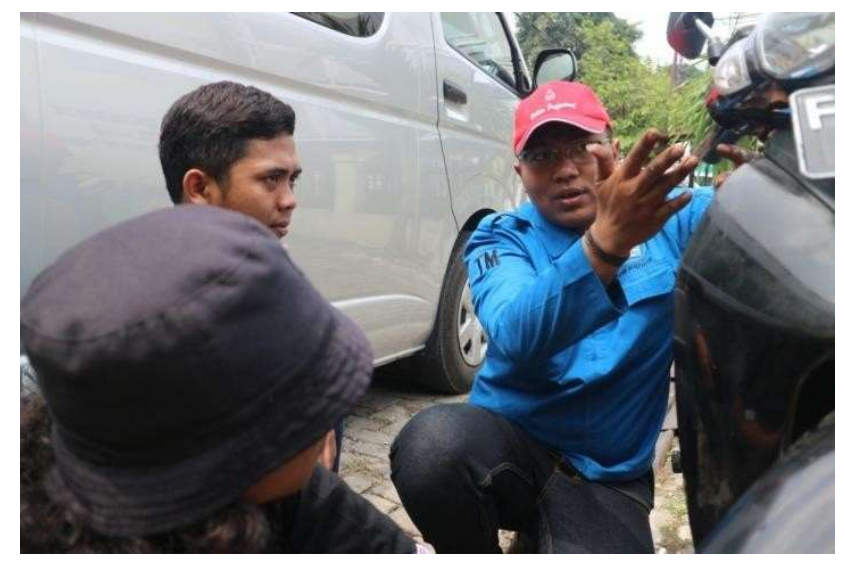

Gambar 3 Poto proses pembekalan materi praktik perawatan sepeda motor oleh mahasiswa

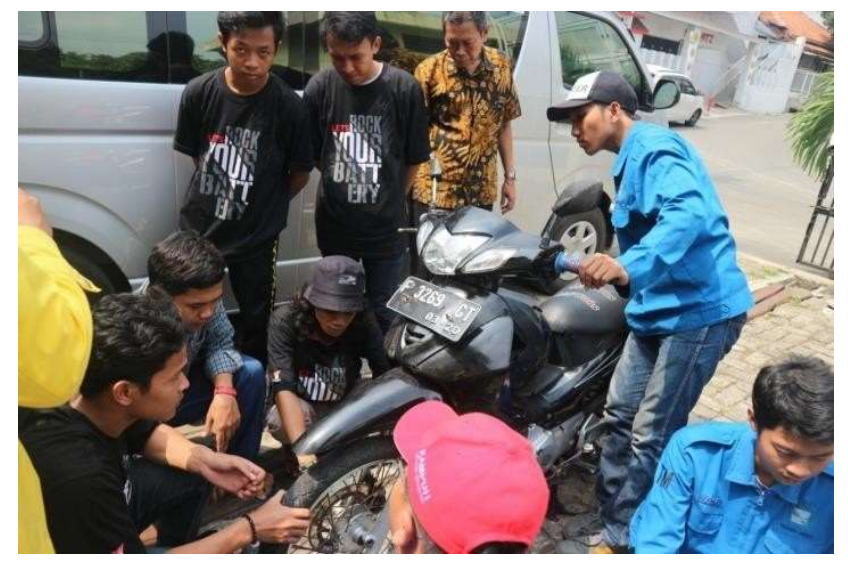

Gambar 4 Poto proses praktik perawatan sepeda motor oleh peserta didampingi mahasiswa

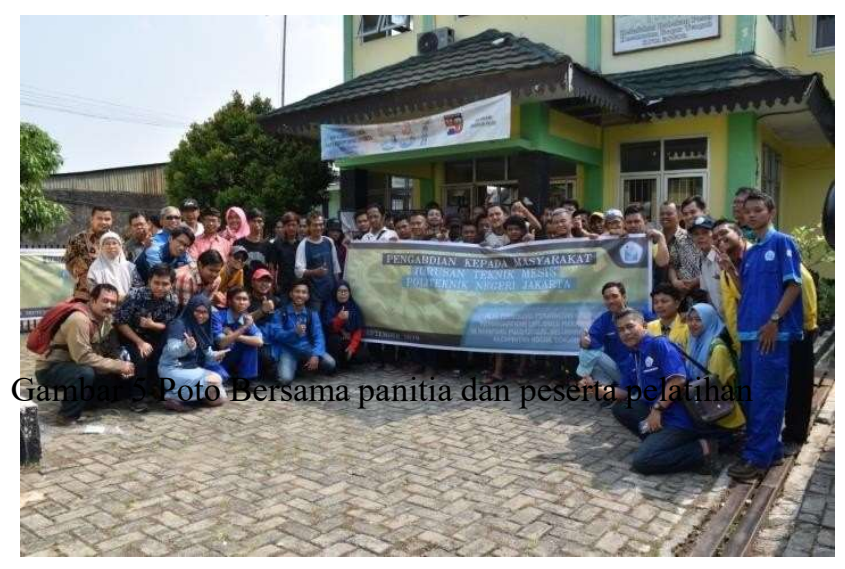

Pertanyaan yang muncul pada saat kegiatan adalah tentang proses atau tahapan pelatihan cara perawatan dasar sepeda motor yang berlangsung secara terus menerus. Untuk mendapatkan ilmu yang mendalam tentang perawatan sepeda motor ini adalah diperlukan kursus, akan tetapi di kegiatan pengabdian ini cukup dalam waktu sehari, dengan instruktur dari dosen yang berkompeten didampingi asisten mahasiwa, sehingga seluruh peserta bisa mendapatkan bimbingan yang intens sampai ke praktik.

Para peserta yang terdiri atas pengamen, pegangguran, dan pemuda putus kerja ini dibina dan diberikan bekal keahlian sebagai wujud tri darma perguruan tinggi khususnya Jurusan Teknik Mesin, Politeknik negeri Jakarta.

Antuasiasme para peserta tidak terbendung, terbukti walapun di tengah terik matahari meraka masih tetap semangat mengikuti jalannya pelatihan dari awal hingga akhir, bahkan ada peserta yang bertekad agar benar-benar memahami materi dengan cara mempraktikannya berulang kali. Salah satu peserta bernama Dedi Supriadi mengungkapkan bahwa ia sangat merasakan manfaat pelatihan tersebut walaupun hanya berlangusng satu hari saja.

Hasil dari pengabdian masyarakat tahun 2019 kali ini diharapkan dapat memberikan manfaat bagi warga kampung Pulo Geulis yang seacara taraf ekonomi ada yang belum sejahtera. 
Dengan hadirnya pelatihan perawatan dasar sepeda motor ini para peserta khusunya yang telah mengikuti pelatihan dapat mengaplikasikan ilmunya dengan memilki atau membuka bengkel motor yang peralatan bengkelnya hasil dari hibah dari Jurusan Teknik Mesin Politeknik negeri Jakarta. Mengingat pelatihan tersebut yang terbilang singkat, pihak panitia akan terus berkoordinasi serta berupaya menindak lanjuti hasil dari pelatihan agar para benar-benar terciptanya jiwa mandiri para peserta untuk menigkatkan taraf ekonomi kususnya bagi para peserta pelatihan.

\section{SIMPULAN}

Pengetahuan dan skill para peserta tentang teknik perawatan sepeda motor meningkat setelah mengikuti kegiatan Pengabdian Kepada Masyarakat ini. Peningkatan pengetahuan dan kompetensi ini disebabkan karena pelatihan yang berlangsung mampu berjalan dengan lancar, terlaksana dengan efektif, para peserta antusias dan gembira selama kegiatan berlangsung, sehingga walaupun para peserta memiliki keterbatasan waktu, namun mereka tetap semangat dan bisa melakukan praktik dari mulai mengganti oli hingga pada tahapan yang sedikit rumit yakni memeriksa karburator sepeda motor.

Peningkatan pengetahuan ini dimonitoiring tidak hanya pada saat mengikuti pelatihan, namun Tim dosen juga melakukan pemantauan setelah kegiatan selesai. Pemantauan dilakukan dengan cara melakukan terus menerus komunikasi dengat perangkat desa, atau staf desa, bahkan ketua warga kampung Pulo Geulis. Pemantauan misalnya apakah penegetahuan dan peralatan yang didapat langsung dirasakan manfaatnya terutama untuk latihan di rumah masing-masing, atau di lokasi lain, agar apa yang diharapkan oleh Tim Dosen Panitia Pengabdian dapat berhasil sesuai tujuan yang ingin dicapai.
Akhirnya, dapat disimpulkan bahwa kegiatan ini sangat bemanfaat bagi masyarakat dalam menyediakan life skill seluruh peserta agar siap menghadapi tantangan hidup ke depan. Jika memiliki suatu keahlian, maka setidaknya orang tersebut minimal bisa bermanfaat untuk dirinya dan umumnya untuk masyarakat sekitar.

Peserta berharap bahwa kegiatan ini terus dilakukan di tahun selanjutnya, karena selain memberdayakan manfaat langsung bagi masyarakat, kita juga mengedukasi warga agar bisa mengembangkan potensinya dengan cara membuka lapangan pekerjaan.

\section{DAFTAR PUSTAKA}

Sunaryo. 2015. Pemberdayaan Masyarakat Melalui PelatihanMekanik Sepeda Motor Di

DesaPulus \& Gumiwang, Kecamatan Sukoharjo, Kabupaten Wonosobo. Jurnal PPKM I

Siswanto. Ibnu, Sudiyanto, dkk. PelatihanPerawatan dan Servis Gratis Sepeda Motor

DalamRangka Dies Natalis UNY ke-49 Tahun 2013.

https://id.wikipedia.org/wiki/Pulo_Geulis 